\title{
Continuing social presence of the dead: exploring suicide bereavement through online memorialisation
}

\section{Louis Bailey, Jo Bell \& David Kennedy}

To cite this article: Louis Bailey, Jo Bell \& David Kennedy (2015) Continuing social presence of the dead: exploring suicide bereavement through online memorialisation, New Review of Hypermedia and Multimedia, 21:1-2, 72-86, DOI: 10.1080/13614568.2014.983554

To link to this article: https://doi.org/10.1080/13614568.2014.983554 \section{(c) 2014 The Author(s). Published by Taylor \&
Francis.}

\section{曲 Published online: 16 Dec 2014.}

Submit your article to this journal $\widetilde{ }$

LII Article views: 2658

Q View related articles $\square$

View Crossmark data $\nearrow$

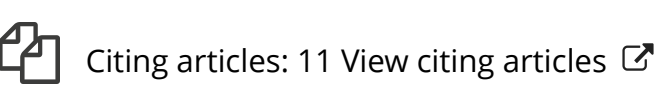




\title{
Continuing social presence of the dead: exploring suicide bereavement through online memorialisation
}

\author{
LOUIS BAILEY ${ }^{\dagger} *$ JO BELL ${ }^{\ddagger}$ and DAVID KENNEDY ${ }^{\ddagger}$ \\ ${ }^{\dagger}$ Hull York Medical School, University of Hull, Hull, UK \\ ${ }^{*}$ Faculty of Arts and Social Sciences, University of Hull, Hull, UK
}

(Received 12 September 2014; accepted 1 October 2014)

\begin{abstract}
The last 10 years have seen a rise in Internet sites commemorating those lost to suicide. These sites describe the life of the deceased and the afterlife of relatives, parents, friends or siblings who have been termed the "forgotten bereaved". It is clear that such sites have implications for continuing bonds and for what many commentators refer to as the continuing social presence of the dead.

This paper presents interim findings from ongoing research which focuses on two aspects of suicide memorial websites. First, we explore the extent to which such sites help us understand how the Internet is enabling new ways of grieving and is, in effect, making new cultural scripts. Second, although there is a large body of writing on the management of trauma there is little evidence-based research. The paper draws on face-to-face interviews with owners of suicide memorial sites (family members and friends) and explores how the establishment and maintenance of such a site is an important part of the therapeutic process and how, for grieving relatives, making or contributing to such sites provides ways of managing trauma in the aftermath of a death by suicide.
\end{abstract}

Keywords: Online memorialisation; Suicide bereavement; Continuing bonds; Postvention.

\section{Introduction}

An act of suicide forces those surrounding it to face huge and terrifying questions about what life means, how to connect with others, how to stop pain from overwhelming us and many other questions that go to the very centre of the human condition (Hollander, 2001). Individuals affected by deep, sudden and shocking loss strive to communicate with others about their loss and to try to make sense of their loss (Shneidman, 1985). Those who are bereaved by suicide are likely to experience additional challenges that do not feature in other types of death, including shock, stigma, blame, guilt and anger (Bell, Stanley, Mallon, \& Manthorpe, 2012; Jordan \& McIntosh, 2011; Ratnarajah \& Maple, 2011) and are therefore forced to endure complicated or traumatic grief (Jacobs \& Prigerson,

\footnotetext{
*Corresponding author. Email: Louis.Bailey@hyms.ac.uk 
2000). The grief of bereaved parents who have lost a son or daughter to suicide will be compounded due to the disruption of the "natural" generational order of death as well as potential guilt, isolation and societal exclusion that may result from the aftermath of suicide (Hollander, 2001; Jordan, 2001). The stigma endured from suicide bereavement may result in a form of disenfranchised grief (Maple, Edwards, Minichiello, \& Plummer, 2013). Valentine (2009) argues that grieving is a discursive activity which involves creative interplay between society's structures and individual agency. The Internet has emerged as a valuable outreach tool for the stigmatised bereaved, enabling them to overcome isolation and find others in a similar position to themselves in order to share memories and experiences, find support and make sense of the events (Chapple \& Ziebland, 2011; Finlay \& Krueger, 2011).

Recent years have seen a significant rise of Internet sites commemorating those lost to suicide. These comprise stand-alone web pages and, increasingly, the use of online social networks, such as Facebook, to mourn and remember the deceased. ${ }^{1}$ Leonard and Toller (2012) have highlighted the significance of online social networking both within the lives of young people and in cases of suicide deaths: "From birth to death, many individuals chronicle their lives online through blogs, pictures, games, Web sites, and social networks. Online spaces, created by the living about the dead, provide a glimpse into often invisible or silent grieving practices". Analysing online practices therefore has clear consequences for suicide prevention and postvention work. ${ }^{2}$

In parallel to this there has been a growing body of work exploring the role of the online environment on contemporary bereavement and memorial practices (Forman, Kern, \& Gil-Egui, 2012; Leonard \& Toller, 2012; Roberts, 2007). A couple of notable pieces of work have examined how users of social networking sites memorialise the deceased online. Carroll and Landry (2010) undertook a qualitative study of how Myspace and Facebook users interact with the deceased online, focusing specifically on how younger people use the online environment in order to maintain connections with those that have died. The authors pay particular attention to the blurring of private messages to the deceased with public displays of mourning, facilitated through the wider online arena, and found that online social networks provide a space for those who are otherwise marginalised by traditional outlets to grieve. Kasket (2012) undertook a document analysis of five "in memory of" Facebook groups and conducted interviews with three bereaved Facebook users in order to contextualise the continuing bonds theory of bereavement and to explore the value of online environments for "deathwork" and bereavement practice. These studies, however, whilst useful, are not specific to suicide bereavement.

Krysinska and Andriessen (2010) examined the types of online support and resources available for people bereaved by suicide and reported a lack of qualitative research in this area which addressed the ways in which online resources and material helps people bereaved by suicide to grieve. Chapple and Ziebland (2011) examined the impact of the Internet on suicide bereavement by interviewing 40 suicide survivors from the UK. These authors highlighted the differing ways in which those bereaved by suicide use the Internet in 
general—examining email usage, use of websites to buy support books and use of online support forums and general social networking sites. They concluded that the Internet is transforming the experience of bereavement by suicide, most dramatically by providing suicide survivors with access to the shared experiences of others. However, Chapple and Ziebland did not focus specifically on the use of individual online memorial sites and environments.

As far as we are aware, no studies to date have undertaken in-depth interviews with the owners of online memorial sites connected to suicide grief and bereavement. Thus this research represents an important new departure. First, it adopts an interdisciplinary approach, drawing together literary studies' focus on how mourning objects are constructed with social science research concerned with meaning making, suicide bereavement and new ways of grieving. Second, it differs from previous research into online memorial sites which has avoided direct contact with site authors or owners and which has focused only on linguistic, textual or visual analysis (see Finlay \& Krueger, 2011; and Lester, 2012). The research considers the significance of the online environment for the grieving process, highlighting the ways in which the Internet enables new ways of managing suicide bereavement, an otherwise private, complex and stigmatised form of grief. The research draws on 11 in-depth interviews with bloggers, website owners and Facebook users who utilise the online networking environment to memorialise loved ones who have died by suicide. The emphasis on survivors' experiences and words is, according to Bell et al. (2012), crucial in postvention work.

\section{Method}

With approval from the faculty of arts and social sciences' ethics committee at the University of Hull, we invited individuals with experience of setting up their own websites in memory of loved ones who have died by suicide to take part in faceto-face interviews. Participants responded to recruitment posts advertised via PAPYRUS Prevention of Young Suicide (a national UK charity working to prevent suicide in young people), Survivors of Bereavement by Suicide (a self-help organisation in the UK which exists to meet the needs and break the isolation of those bereaved by the suicide of a close relative or friend) and the University of Hull website. Those who wanted to take part contacted the research team who then provided further information and details.

Eleven people bereaved by suicide were interviewed. The sample included: three men and eight women; people who were bereaved recently (the most recent being approximately 5 months) and people who were bereaved some years ago (up to 4 years); people from different social backgrounds, geographic locations and ages (ages ranged between 30 and 60 years). The sample also included those who had lost a child, a sibling or a friend. Following written consent, participants were asked to talk about their experience of bereavement and what specifically had motivated and inspired them to create online sites. They were asked about their perceptions of the benefits of doing this and the wider implications for understanding suicide grief and the role of the Internet. Participants were also 
asked to talk about their perceptions of any negative aspects of this sort of online activity. People were interviewed in a place of their choice for between one and three hours.

Interviews were recorded with permission and followed a semi-structured narrative style (described by Cooper, 1999) which allowed for modification of the order of questions, capitalising on the responses of the participant and promoting logical progression. Each interview began by asking questions about the circumstances of the death. Hawton et al. (1998) and Cooper (1999) argue that the unburdening of this emotionally charged subject provides a starting point for looking back on the events leading up to the death. Emphasis was placed on encouraging participants to talk freely about their experiences and to "tell the story" in the way they chose (Owens, Lambert, Lloyd, \& Donovan, 2008).

All interviews were fully transcribed and the authors read the data, constructed a coding frame and examined themes across the data set as well as within the context of each individual interview. A qualitative interpretive approach was taken, combining constant comparison with thematic analysis (Chapple \& Ziebland, 2011; Glaser \& Strauss, 1967; Green \& Thorogood, 2004).

\section{Findings}

An interesting and unexpected finding amongst our sample was that Facebook was by far the most commonly used resource (reported by all but one of our respondents). Some had kept and sustained existing Facebook accounts belonging to the deceased, others had created new pages in memorial to the deceased. Two of our participants had developed their own websites. For all of our participants these resources served as a memorial to their loved one and as a means of bringing people together, gaining support and reaching out to others. Some also used these resources for awareness raising and fundraising. Through their narratives, participants described the various ways in which the Internet has transformed elements of their experience of suicide grief. One common aspect was to keep the deceased's page going as a way of keeping the deceased "alive". We discuss these themes with representative data extracts in the following sections.

In terms of the circumstances under which sites were initiated, responses varied: one parent got the idea from a neighbour; another parent was given the idea by the police who delivered the news that her son had died; others did so on the recommendation of friends. Some started using Facebook immediately; others waited a while (up to a year for one participant).

Many of our respondents described how Facebook was initially used to inform wider networks outside of the immediate family about the death. This included friends and acquaintances of the deceased who were not necessarily contactable by phone but who were instead found via the deceased's Facebook page. The instantaneous nature of Facebook meant that news about the death spread relatively quickly and saved the bereaved from having to make a series of difficult phone calls to people who they were not otherwise close to or in touch with. 
In the following excerpt, a mental health worker found out about a neighbour's suicide via the deceased's Facebook profile and describes what followed:

so what happened at first was there's just this, the natural outpouring of grief, comments about how he' $\mathrm{d}$ be missed ... they were just going there to express themselves and how they felt about losing him ... lots of people gravitated there to try and make sense of what was happening, wanting to say their bit to him ... wanting to say goodbye. (OSM012f)

For many of the bereaved, losing a loved one to suicide is particularly difficult to comprehend and accept. There is a sense from survivors that the deceased have been taken away from them too soon and that they have died before their time. In this and other instances, Facebook enabled the bereaved the chance to say their final farewells to the deceased in the hopes of starting to come to terms with the death and ensuing loss.

In the following example, a mother describes the ways in which she and her family used Facebook in order to seek solace in the first few weeks following her son's death and whilst they were waiting for the inquest into his death:

people found out by the next morning that he'd died ... it all got round by Facebook and people were writing on it straightaway ... and we would all read them and get upset, or read them and laugh ... we did ask people to put photos on and ... their memories of Mark and ... the funny stories really comforted us ... Facebook page ... enabled us to get together and laugh and ... actually share some nice memories. I think it kept us going that first two weeks. (OSM010)

In this and other examples, Facebook enabled participants to talk with other family members and friends of the deceased online-either via private messaging or by interacting with one-another and the deceased by posting comments, photographs and links onto the deceased's "wall". Participants described feeling comforted as they shared happy memories of the deceased with others onlineoften triggered by the posting of favourite songs and other items which helped them to remember the deceased. The use of Facebook enabled participants to connect with others affected by the suicide in order to both seek and provide emotional support. Activity was particularly heightened in the first month following the death and the platform served as a key mechanism for bringing people together for the purpose of remembrance and to initiate the grieving process.

Participants in our study talked about how the use of the sites continued beyond the immediate aftermath of the death and how the functions and nature of activity evolved. Firstly, the emotional and therapeutic functions of the site (reaching out, seeking support and bringing people together) expanded as users continued to share memories and messages long after the death had occurred. Secondly, participants used the pages for sharing information, signposting support and raising awareness. Some, like this mother who lost her son to suicide the previous year, had initiated support forums and incorporated links to suicide prevention or suicide bereavement charity pages and fundraising events: 
there's always something going on there ... one of his friends is doing a fundraising event ... my sister-in-law did a sponsored walk ... Ben and his friends ... they've got a just giving page and that's already got quite a lot on it ... It's a real forum for everything, everything you think of really ... It's evolving all the time ... for me that was very much a healing process. (OSM014f)

Parents, in particular, cited the cathartic effect of keeping busy and staying proactive. For this parent, setting up a stand-alone website in his son's memory enabled him to reach out to others and become involved in suicide prevention efforts. This had knock-on consequences for enabling him to stay connected to his son and manage his own grief in the process:

I am passionate about suicide prevention and ... letting people know there is stuff out there but it's also a way of me still being involved in Harry and Harry being involved in my life on a day to day basis and I'm very proud to mention his name and to try and get across the message ... it's given me things to do ... if I needed a moment with Harry I could then do something on the site ... so that helped from that point of view ... [Harry's site] is where I put my energy into if I'm feeling shit ... and, you know ... it's cathartic. (OSM016m)

For these parents and others, utilising social media for the purposes of charitable work made them feel like they were doing something worthwhile. There was the feeling that even though it was too late for their own child, they were spurred on to prevent the deaths of other young people who may be at-risk. A common refrain was the need make their child's death meaningful, for something good to come out of an otherwise unfathomable and heartbreaking tragedy. This parent described setting up a memorial page on Facebook both in order to remember her son, and thereby continue that connection, and in order to do something for him posthumously:

I wanted him to be remembered ... because he ... left so little of himself ... also it's kind of like making up to him ... and saying well I'm going to do this for you Carl ... just to ... acknowledge the pain he went through. (OSM015)

Many of the participants' accounts were underlined with guilt. Parents, in particular, talked about the regret they felt about not being able to prevent their child's death, the anger they felt towards their child, and the shame they felt for trying to get on with their lives. Contributing to this was the stigma surrounding suicide which significantly impacted their grieving processes and experiences. Here, a mother talks about people's reactions when she mentioned her son's death:

if I do say he killed himself, people almost just change the subject ... you might as well have said, you know, he was a paedophile or something. I mean it just, people just can't cope with.

(OSM011)

She found the silence of others-both strangers and close friends alikeparticularly difficult. Elsewhere, a father described how neighbours would cross the street in the first few months after his son's death in order to avoid him. Suicide still remains one of society's biggest taboos, inducing otherwise 
compassionate and empathetic people to sidestep conversation for fear of not knowing what to say or else being scared of saying the "wrong" thing. Disenfranchised grief-namely, grief that is not recognised or acknowledged by society - can have huge repercussions for those intimately affected by suicide and can result in their gradual withdrawal from social life (Doka, 1989). As Goffman notes with regards to the stigmatised subject: "Lacking the salutary feed-back of daily social intercourse with others, the self-isolated can become suspicious, depressed, hostile, anxious and bewildered" (Goffman, 1963, p. 13). The stigmatised bereaved become deprived of crucial support from family and friends and, as a result, miss out on the cathartic effects of sharing their grief. This, in turn, can both interrupt and compound the grieving process.

Significantly then, Facebook comes into its own as providing a platform for suicide survivors to find others in a similar situation, people who they would not otherwise encounter in their day-to-day life:

I had this huge desire to ... find and connect with other people that could understand what I was going through ... writing about this and sharing and letting people know what it's like. (OSM011f)

The participants were able to explore their grief with others from the comfort of their own homes. The online environment also served to free up some of the inhibitions that they otherwise felt when talking to strangers and even friends about their loss, affording them an openness that they did not get elsewhere. Some described feeling comforted by the fact that they no longer felt as alone and isolated whilst others felt that talking with other survivors gave them important insights which helped with their grieving process.

\subsection{Keeping the deceased alive}

The most common motivating factor amongst our respondents for initiating, sustaining and maintaining website and Facebook pages was the need to stay connected to the deceased and to keep the deceased alive: many described how they used the sites to communicate with lost loved ones and their friends both in the immediate aftermath and long after the death. Accounts of others communicating with the deceased via Facebook were common:

People go up there and put mementoes on and they'll say on Facebook, been to see you today Mark ... yesterday I went up and I just chatted to him ... now more three and a half years on ... they write and say really miss you Mark or I'm doing this and it reminded me of you ... he's still being included in what his friends are doing. (OSM010f)

These on going relationships often included humour and playfulness as in this example of a father who, on his birthday, asked his deceased son via Facebook "where's my card?" (OSM017m). Being able to stay connected and maintain a relationship with the deceased was crucial, as was remembrance: "To keep him alive. ... To ... still be able to talk to him. ... His friends." (OSM010f). Many spoke too of the therapeutic benefits of communicating in this way with the deceased: 
I said Carl I miss you sort of thing ... like somewhere, somewhere in the ether ... he might actually read it and ... realise how much we loved him. (OSM015f)

Keeping the deceased alive on Facebook was a way of working against loss. Our data illustrates the notion of Facebook and other online venues replacing traditional mourning objects-namely, physical objects that are imbued with particular emotional resonance and which consequently take on additional significance after the death of a loved one. These can be objects that belonged to the deceased, such as a lock of hair or a watch, or repository objects, such as a photograph album or gravestone, which serve as visual and material markers for representing the identity and memory of the deceased. Online venues are preferred by our sample because of their potential for facilitating continuing bonds and connectedness in a way that traditional mourning objects are unable to do, as the following extract from a bereaved parent demonstrates:

it's better than a... photo album ... because... he was a computer person so... it made sense,
yeah... it was a little bit of... him staying on ... it was some sort of avenue through to him, I
felt... a couple of videos there... and you can play them and it's... like he's still there
because you can hear him talking... you actually hear the... voice, it's like... bringing him
back, you know, even for a second or a couple of minutes and... that's incredible ... and the
thing is it's all so easily accessible rather than being... I don't know, in a box. (OSM015f)

For this mother, interacting with her son's Facebook page was preferable to looking through old photograph albums, which she said were stacked on top of the wardrobe gathering dust. Facebook served as an interactive repository which enabled her to look at and listen to her son via a range of photographs and videos which had been uploaded by him when he was still alive as well as subsequently by friends after his death. Being able to see and hear his voice helped to "bring him back" and made her feel close to him again, providing her with great comfort during her grief.

In addition, Facebook, for some, revealed different sides of the personality of the deceased that were previously unknown to the bereaved:

in a way it's enabled me to access his ... personal life ... Facebook has enabled me to see ... the side of Carl that I didn't know about ... so from that point of view it, it is good. (OSM015f)

Seeing new photographs provided comfort to these participants and contributed to their on going sense of connectedness as they felt that they were still getting to know their loved one. This, in turn, meant that their memories and relationship were still evolving as an active process and in the present rather than something that occurred in the past. Another respondent described collating the photographs posted on Facebook and incorporating them into her son's memorial service. This was the first time that she had seen many of the photographs shared.

At present, if a Facebook user dies, other Facebook users-family, friends and even those not connected to the deceased — can make a "memorialisation request" to the site administrators in order to request that the deceased's profile be converted from an "active" page into a "memorial" page. If this action is 
implemented, only confirmed friends of the deceased can see the profile and the login feature is disabled, preventing anyone from logging into the account and changing the profile page. As a result, the profile is left unchanged. Those connected to the deceased can, however, still post messages, tributes and items (such as photographs and video links) to the deceased's page. However, in keeping with the need to keep their loved ones "alive", many respondents were resistant to the option to have the "live" profile page of their loved ones "memorialised" post-death:

I don't want Mark's to be a memorial ... To us a memorial site is just more proof that is in your face that he's died ... I would be horrified if they made it a memorial site ... it's different ... there's all his ... likes and dislikes on there and stuff he's ... you know this is his personality ... favourite quotations ... it's still Mark ... There's a difference. (OSM010f)

The extracts presented above illustrate the importance of the deceased's continuing presence in the psychic and social lives of loved ones and suggests that attachment and detachment work in ways that diverge from the dominant "stage" models of bereavement. As in Klass et al's (1996) work on mourning, the deceased goes on living and talking inside the living - a point we will return to later.

\subsection{Negative aspects}

Finally, our data gave rise to insights about the ways in which the Internet might compound grief and make the grieving process potentially more difficult. In a discussion on how the Internet is providing new ways of grieving, it is important that these aspects are acknowledged and explored.

One of the important findings in our study was that family members differed in the ways in which they chose to use and contribute to the sites. Some actively chose not to use the site altogether. One parent described how her son refused to look at his deceased brother's Facebook page ("I think he's trying to forget about him"). One respondent described the Facebook page as his "lifeline", but others in the family had never looked at it; one family member had chosen to stop going on altogether after previously being actively involved in the maintenance of the site whilst another younger member of the family had asked to join it but had been prevented by others in the family.

Another participant described how the page was initially public but that they changed the settings to private because they received outpourings of grief which they felt were not genuine. They also feared it would provoke copycat suicides. Linked to this, another participant described family tension around adding friends to the Facebook page. The dangers of becoming overly attached to sites were highlighted by a further respondent who described her experience of "double loss" when the Facebook page she created for her son disappeared unexpectedly.

This participant described her anger at others when she began to notice activity on the Facebook page had started to wane. Her distress reiterates the importance of remembrance and keeping the deceased alive for some people in managing their grief: 
when it started quieting down ... that was a bit tough ... because it's like have people forgotten? Don't people care? (OSM013f)

This online silence was interpreted by the respondent as a sign that others had "forgotten" about the deceased and had moved on with their lives. At the root of this is the dread that, for the participant, with forgetting comes the possibility of erasure and therefore the final "death" of the deceased. As Vivian notes:

Forgetting ... continues to signify a loss, absence or lack—not simply of memory but of live connections with a tangible past. (Vivian, 2010, p. 5)

This respondent goes on to describe the loneliness she experienced following the diminished activity on Facebook:

My grieving process feels very lonely even though I've got all these people I've met ... the dangerous thing about social networking is the isolation ... so they feel like conversations but ... ultimately you're sat ... at home on your own reflecting on all this ... you're ... left with your own grief, you've got all your own thoughts, usually with people knowing, multiple people and ... I think that's a tricky position to be in. (OSM013f)

This extract reveals the deceptiveness of social media-interacting with people, and expressing and sharing grief in a public arena did little to alleviate (and perhaps contributed to or even exacerbated) this participant's sense of physical and private isolation.

\section{Discussion}

Suicide presents a challenge to the meaning of living (Hollander, 2001). The identity of a suicide survivor has been altered by the tragedy in a way that profoundly reshapes who they are. As they are forced to rebuild their selves and relatedness to the world, they must reconstruct an identity which incorporates the tragedy and which goes some way towards honouring the loss (Hollander, 2001). This identity cannot be reconstructed without dialogue about the meaning of the loss and the struggle to make sense of it and this process of meaning-making relies on communication (Hollander, 2001). It is crucial that survivors find a place to share their feelings and experiences. However, due to the social stigma surrounding suicide, this may not always be possible via face-to-face interaction. The Internet comes into its own as a place which enables conversation about otherwise sensitive and "taboo" topics, the relative anonymity of the online world serving to free up inhibition (Suler, 2004), enabling suicide survivors to post things which might otherwise be met with silence or chastisement. The bereaved can then connect with others who are going through a similar situation, people who may live hundreds or thousands of miles away.

Our data has shown how the Internet allows survivors to construct and refine representations of themselves and their loved ones and, in the process, emerges as an important tool for helping to build new identities through loss. The use of the social media sites enables others to develop a narrative to explain the events in their lives. Participants have in common the need to exteriorise core experiences 
of trauma, bereavement and grief through the sharing of these events with others. It is clear from this study that meaning-making is of crucial importance for suicide survivors. Meaning-making is therefore predominantly social but also cuts across the realms of the personal, emotional and practical. The representation of the deceased in the social and psychic world of the bereaved person (Klass, Silverman, \& Nickman, 1996) is validated through the sharing of that representation in the social and psychic worlds of other people. In this sense, the use of social media - as shown in some of the quotations-goes some way towards answering the question of where one puts one's feelings (love, grief, etc.) after a death. The online pages referred to in our study served as repositories for the emotional lives and connections of the bereaved.

The use of social media converges with an increasing acknowledgement of a continuing bond between the deceased and the bereaved (Field \& Filanosky, 2009). The theory of continuing bonds was first articulated by Klass et al. (1996) to argue against the healthy/unhealthy divide regarding grief and to instead highlight the continually evolving nature of relationships between the bereaved and the deceased which do not necessarily end, even after death. Klass (2006) goes on to highlight the importance of the social element of continuing bonds within the bereavement process. Continuing bonds is generally referred to as in keeping with the constructivist model of grief (Neimeyer, Baldwin, \& Gillies, 2006), which goes against well established and still dominant stage models of grieving and bereavement (e.g. Kubler-Ross, 1969). As Maple et al. (2013) point out, these older stage-based paradigms continue to inform public policy and dominate Western and lay professional expectations of bereavement (McCabe, 2003). In this narrow understanding, the pressure to resolve grief limits opportunities for remembering the child and involving others. The use of social media, as we have described it, demonstrates an emerging acceptance of the constructivist model of grief; the physical bond is gone but a virtual presence remains. Memorial sites and Facebook pages help the bereaved to see how events in the past can continue to have value and meaning in the present and for the future. As Maple et al. (2013) argue, the constructivist model of grief is founded on the idea of transformation. That is, transformation occurs both within the bereaved and socially which involves "the integration of the representation of the deceased into the social and psychic worlds of the bereaved" (Klass et al., 1996, p. 58). From our research it is clear that this is assisted by the relationship between inner representations of the bereaved and outer representations online.

Walter (1996) argues that constructing a durable biography of the deceased via social contact and continued conversations assists the bereaved to re-integrate them into their lives. The online platform, Facebook, emerged as a popular site amongst participants and many of those interviewed turned to the profile pages of their deceased loved ones in order to assist with their grief and memorialisation practices. The instantaneous nature of Facebook allowed the bereaved to find support and spread information quickly and the momentum generated, particularly in the initial days and weeks following the death, served as a reassuring influence. In addition, for parents of the bereaved, Facebook enabled them to connect with those who they were otherwise not in touch with, such as friends of the deceased, 
and to find out about other aspects of their son or daughter's personality and lived experiences. As Kasket (2012) notes, Facebook is an ideal platform to enable this process of social integration to continue, overcoming the obstacles presented by increasing geographical distance between family members to enable new opportunities for "mediator deathworkers":

When the community of mourners gathers on a social networking site, their memories and actions serve to evolve and add to the social identity, the durable (digital) biography, that was begun by the deceased individual during his or her life. (Kasket, 2012, p. 67)

Linked to this, neither the self of the bereaved nor the represented personhood of the deceased are fixed entities and the process of making and maintaining a site or a Facebook page makes both susceptible to change. A Facebook page in particular reveals authorship to be an ongoing social process in which many individuals can contribute to the establishment and maintenance of a psychic space. The everchanging and evolving nature of the deceased's Facebook page proves to be particularly comforting for the bereaved and serves to "keep the deceased alive".

Viewing an online memorial site as an ongoing process has emerged as having a significant impact on trajectories of healing. Alongside the social networking potential, the role of a memorial site as a private space for bereaved people to visit is worth reiterating:

A display monitor where one might linger early in the morning when one is no longer able to sleep, a place that is always available and open, unlike a physical site where a visit in the middle of the night would be totally inappropriate. Knowing that strangers [or friends] are visiting, that the counter is higher today than it was yesterday, that someone, somewhere is thinking about the lost [person], that perhaps someone has taken the trouble to write and offer words of comfort-all this is soothing in and of itself. (Finlay \& Krueger, 2011, p. 40)

And, as Kasket (2012) notes, Facebook enables mourning to take place in the same "space" as that occupied by the living, enabling interaction to continue "with the same co-constructed representation of self created during that person's life, rather than with a new, eulogised representation of the person created by someone else in a virtual cemetery" (p. 63). This, in part, may explain the resistance that some of the bereaved felt with regards to the option of having the "live" page of their loved one memorialised post-death.

\section{Conclusion}

Suicide deaths are particularly difficult to grieve. However, the use of websites and Facebook pages assists the grieving process because they allow for the exteriorisation of feeling. Trauma can be alleviated by the process of making and managing a new cultural script—one's attention is literally elsewhere. Trauma can also be alleviated because the making of such sites is a process of discovery in which the bereaved can find out about different aspects of the deceased's personality through postings by others who have known them. Finally, trauma can be alleviated because the memorial site or Facebook page becomes a mourning 
object in its own right. Online memorials therefore transform the experiences of the bereaved and open up new ways of grieving and managing trauma.

Our study reveals the ways in which online memorials fulfilled a range of functions, which spanned across social, emotional and practical realms. Online memorialisation enabled the bereaved to connect with others who were going through a similar process of grief and loss and enabled a form of uncensored selfexpression which was not comparable with face-to-face conversations. However, whilst some participants found solace via the Internet, others were wary of it and differences in Internet use, perceptions and ways of grieving were shown to cause tension within some families. Whilst the constructivist model of grief is useful for the consideration of new forms of grieving — as enabled through the Internet—it is important to acknowledge other frameworks for enabling grief. Again, whilst the numerous benefits of online memorialisation cannot be doubted, it nevertheless presents a number of problems and issues which need addressing, particularly in the area of postvention. It is crucial that both bereavement workers and the bereaved are informed about the potential risks of utilising Facebook for the purposes of aiding grief and memorialisation. As our study has revealed, suicide survivors have to negotiate the following pitfalls when engaging with online memorials: tailing off interest due to time lapse, feeling responsible for the thoughts and actions of others, censorship, unwanted interest from strangers, changes to the site without their consent, removal of the page without their consent. The last point is of particular concern and the double loss experienced by the bereaved-in terms of the loss of their loved one and the loss of their Facebook page - can serve to compound the grief; the page representing not only a support mechanism but also a virtual mourning object and, crucially, a vehicle for enabling continuing bonds. In the absence of a loved one, the Facebook page remains all that is left, bearing traces of their personality and fragments of their thoughts, humour and virtual selves-it becomes an extension of and substitute for the deceased. It is therefore crucial that suicide survivors are fully informed and prepared prior to engaging with the online environment and should not solely rely on online networking for the purposes of suicide bereavement and postvention support. Those engaged in postvention work should consider the ways in which the Internet may serve to delay, disrupt, distract from and potentially exacerbate the grieving process.

Chapple and Ziebland (2011) argue that a key feature of online memorials is that they are modifiable projects unbounded by the local space that physical memorials inhabit, and that their changeability is ideal for keeping the deceased "alive". Our data highlights numerous instances of Facebook replacing traditional mourning objects. For many participants in our study, Facebook is much more than a photograph album - the preferred mourning object. It enables the bereaved to commemorate their loved ones but also opens up a new space for facilitating continued bonds via the virtual space. Participants in our study were driven to create virtual memorial spaces by a need to maintain a relationship with the person who had died and to ensure that they were not forgotten. Adopting a "Freudian" view, we may ask-do Facebook pages function as the acceptance of a symbolic substitute for the deceased after a process of detachment? Or perhaps 
detachment does not occur or else happens differently. What are we to make of this extension of private emotional and social space? Are the pages "mourning objects"? To what extent does the establishment and maintenance of virtual mourning objects (Finlay \& Krueger, 2011) assist survivors in explaining the suicide; making sense of separation; and locating the dead appropriately within survivors' own biographies? Are we witnessing the emergence of what Walter (2014) terms "online angels" in terms of the "real" person being deceased but their "virtual" (Facebook) counterpart living on? Instead of traditional perceptions of heaven, purgatory and hell, do we now have an additional space within the contemporary spiritual psyche - the ethereal space of the Internet-where the bereaved linger and continue to interact with the deceased?

\section{Acknowledgements}

The authors would like to thank the Wellcome Trust and the University of Hull for supporting this research, as well as PAPYRUS Prevention of Young Suicide (a national UK charity working to prevent suicide in young people) and Survivors of Bereavement by Suicide (a self-help organisation for suicide survivors in the UK) for promoting the research by listing a call for participants via their website and networks. Lastly, we would like to thank the participants themselves, without whom this research would not have been possible.

\section{Funding}

This work was supported by the Wellcome Trust under [grant number 102615/Z/13/Z].

\section{Notes}

[1] In February 2014, 10 years after it was founded, Facebook had 1.23 billion users worldwide. Source: Kiss, J. "Facebook"s 10th birthday: from college dorm to 1.23 billion users. The Guardian, Tuesday, 4 February 2014. http://www.theguardian.com/technology/2014/feb/04/ facebook-10-years-mark-zuckerberg. Last accessed: 18 June 2014.

[2] "The Durkheim Project", funded by the Defense Advanced Research Projects Agency (DARPA), analyses the social media data of military veterans in order to predict, with the goal of preventing, suicide. More information about the project can be found here-http://www. durkheimproject.org/

\section{References}

Bell, J., Stanley, N., Mallon, S., \& Manthorpe, J. (2012). Life will never be the same again: Examining grief in survivors bereaved by young suicide. Illness, Crisis, and Loss, 20(1), 49-68. doi:10.2190/IL.20.1.e

Carroll, B., \& Landry, K. (2010). Logging on and letting out: Using online social networks to grieve and to mourn. Bulletin of Science, Technology \& Society, 30(5), 341-349. doi:10.1177/0270467610380006

Chapple, A., \& Ziebland, S. (2011). How the internet is changing the experience of bereavement by suicide: A qualitative study in the UK. Health, 15(2), 173-187.

Cooper, J. (1999). Ethical issues and their practical application in a psychological autopsy study of suicide. Journal of Clinical Nursing, 8(4), 467-475. doi:10.1046/j.1365-2702.1999.00276.x

Doka, K. (1989). Disenfranchised grief: Recognising hidden human sorrow. Lexington, KY: Lexington Books. Dyregrov, K., \& Dyregrov, A. (2005). Siblings after suicide-'The forgotten bereaved'. Suicide and LifeThreatening Behavior, 35(6), 714-724. doi:10.1521/suli.2005.35.6.714

Field, N. P., \& Filanosky, C. (2009). Continuing bonds, risk factors for complicated grief, and adjustment to bereavement. Death Studies, 34(1), 1-29. doi:10.1080/07481180903372269 
Finlay, C. J., \& Krueger, G. (2011). A space for mothers: Grief identity construction on memorial websites created by SIDS parents. Omega, 63(1), 21-44.

Forman, A. E, Kern, R., \& Gil-Egui, G. (2012). Death and mourning as sources of community participation in online social networks: R.I.P. pages in Facebook. First Monday, 17(9). Retrieved from http://firstmonday. org/htbin/cgiwrap/bin/ojs/index.php/fm/article/viewArticle/3935. Last accessed: 17 November 2014. doi:10.52 10/fm.v0i0.3935

Glaser, B., \& Strauss, A. (1967). The discovery of grounded theory. New York, NY: Aldine.

Goffman, E. (1963). Notes on the management of a spoiled identity. New York, NY: Pocket Books.

Green, J., \& Thorogood, N. (2004). Qualitative methods for health research. London: Sage.

Hawton, K., Appleby, L., Platt, S., Foster, T., Cooper, J., \& Malmberg, A. (1998). The psychological autopsy approach to studying suicide: a review of methodological issues. Journal of Affective Disorders, 50, 269-276. doi:10.1016/S0165-0327(98)00033-0

Hollander, E. M. (2001). Cyber community in the valley of the shadow of death. Journal of Loss and Trauma, 6(2), 135-146. doi:10.1080/108114401753198007

Jacobs, S., \& Prigerson, H. (2000). Psychotherapy of traumatic grief: A review of evidence for psychotherapeutic treatments. Death Studies, 24(6), 479-495. doi:10.1080/07481180050121462

Jordan, J. R. (2001). Is suicide bereavement different? A reassessment of the literature. Suicide and LifeThreatening Behavior, 31(1), 91-102. doi:10.1521/suli.31.1.91.21310

Jordan, J., \& McIntosh, J. (Eds.). (2011). Grief after suicide: Understanding the consequences and caring for the survivors. New York, NY: Routledge.

Kasket, E. (2012). Continuing bonds in the age of social networking: Facebook as a modern-day medium. Bereavement Care, 31(2), 62-69. doi:10.1080/02682621.2012.710493

Klass, D., Silverman, P., \& Nickman, S. (Eds.). (1996). Continuing bonds: New understandings of grief. Washington, DC: Taylor \& Francis.

Klass, D. (2006). Continuing conversation about continuing bonds. Death Studies, 30(9), 843-858. doi:10.1080/ 07481180600886959

Krysinska, K., \& Andriessen, K. (2010). On-line support and resources for people bereaved through suicide: What is available? Suicide and Life-Threatening Behavior, 40(6), 640-650. doi:10.1521/suli.2010.40.6.640

Kubler-Ross, E. (1969). On death and dying. London: Tavistock.

Leonard, L. G., \& Toller, P. (2012). Speaking ill of the dead: Anonymity and communication about suicide on mydeathspace.com. Communication Studies, 63(4), 387-404. doi:10.1080/10510974.2011.629274

Lester, D. (2012). Bereavement after suicide: a study of memorials on the Internet. Omega, 65(3), 189-194.

Maple, M., Edwards, H. E. Minichiello, V., \& Plummer, D. (2013). Still part of the family: The importance of physical, emotional and spiritual memorial places and spaces for parents bereaved through the suicide death of their son or daughter. Mortality, 18(1), 54-71. doi:10.1080/13576275.2012.755158

McCabe, M. (2003). The paradox of loss. Westport, CT: Praegar.

Neimeyer, R. A., Baldwin, S. A., \& Gillies, J. (2006). Continuing bonds and reconstructing meaning: Mitigating complications in bereavement. Death Studies, 30(8), 715-738. doi:10.1080/07481180600848322

Owens, C., Lambert, H., Lloyd, K., \& Donovan, J. (2008). Tales of biographical disintegration: How parents make sense of their sons' suicides. Sociology of Health and Illness, 30(2), 237-254. doi:10.1111/j.14679566.2007.01034.x

Ratnarajah, D., \& Maple, M. (2011). Learning from the bereaved by suicide in the face of stigma. In K. McKay \& J. Schlimme (Eds.), Making sense of suicide. Oxfordshire: Interdisciplinary Press.

Roberts, P. (2007). Here today and cyberspace tomorrow: Memorials and bereavement support on the web. Generations, 28(2), 41-46.

Shneidman, E. (1985). Definition of suicide. New York, NY: Wiley.

Suler, J. (2004). The online disinhibition effect. CyberPsychology and Behavior, 7(3), 321-326. doi:10.1089/ 1094931041291295

Valentine, C. (2009). Bereavement narratives: Continuing bonds in the twenty-first century. London: Routledge. Vivian, B. (2010). Public forgetting: The rhetoric and politics of beginning again. Pennsylvania: Pennsylvania State University Press.

Walter, T. (1996). A new model of grief: Bereavement and biography. Mortality, 1(1), 7-25. doi:10.1080/ 713685822

Walter, T. (2014, April 9-10). Old mourners, new mourners. Keynote address, Death Online Conference, Durham: University of Durham. 